\title{
Genetic Syndromes of Severe Insulin Resistance
}

A Melvin, S O’Rahilly and DB Savage.

Metabolic Research Laboratory, Wellcome Trust MRC Institute of Metabolic Science, University of Cambridge, Cambridge, UK.

\section{Short title:}

Severe insulin resistance syndromes

\section{Correspondence to:}

Dr. David B. Savage, University of Cambridge Metabolic Research Laboratories, Wellcome Trust-MRC Institute of Metabolic Science, Box 289, Addenbrooke's Hospital, Cambridge CB2 OQQ, UK.

Tel: +44 1223 367923/ Email: dbs23@medschl.cam.ac.uk 


\begin{abstract}
Insulin resistance underpins the link between obesity and most of its associated metabolic disorders including type 2 diabetes, fatty liver disease, dyslipidaemia and cardiovascular disease. Despite its importance and extensive scientific endeavour, its precise molecular pathogenesis remains unclear. Monogenic syndromes of extreme insulin resistance, whilst rare in themselves, can provide unique insights into the pathogenesis of human insulin resistance. Severe insulin resistance syndromes are broadly classified into three categories: lipodystrophies, primary insulin signalling defects or complex syndromes including severe insulin resistance. Genetically confirmed classification has facilitated the identification of robust diagnostic biochemical features accelerating accurate clinical diagnosis. Interestingly the biochemical features of lipodystrophies are far more closely aligned to what is seen in prevalent forms of insulin resistance than those of primary insulin signalling defects, suggesting that lipodystrophy could be a relevant model for common disease. This assertion is supported by genome-wide association data indicating that SNPs associated with fasting hyperinsulinemia and metabolic dyslipidaemia, are strongly associated with a subtle reduction in hip fat, suggesting that subtle forms of lipodystrophy are likely to be a significant contributor to prevalent insulin resistance.
\end{abstract}




\section{Introduction}

Severe insulin resistance syndromes(SIRS) are a complex group of disorders with impaired cellular responsiveness to insulin manifesting as reduced biological activity to a given concentration of the hormone(1). The normal pancreatic response to insulin resistance(IR) is to increase beta cell insulin secretion(2). Insulin is measurable in plasma and a fasting or glucose stimulated level is often sufficient to make the diagnosis of IR(3). However, insulin is infrequently measured in clinical practice, and often only considered after an individual has presented with one of the hallmarks of chronic hyperinsulinemia. The first of these are cutaneous manifestations of IR including acanthosis nigricans, a velvety hyperpigmented thickening of the skin and acrochordan's (skin tags) which are fibrous dermal benign tumours often localised to skin creases $(4,5)$. The purported pathogenesis relates to the cross reactivity of insulin with the IGF-1 receptor(6). Polycystic ovaries, menstrual irregularities and hyperandrogenism are prevalent in syndromes of severe IR and often constitute the primary clinical manifestation in women. Hyperinsulinemia has been implicated in the pathogenesis of PCOS (polycystic ovary syndrome); a notion supported by improvements in PCOS features in states of reversible hyperinsulinemia such as type B IR due to insulin receptor autoantibodies $(7,8)$. Another trait commonly observed in states of severe IR is altered glucose homeostasis. Impaired glucose tolerance and diabetes mellitus develop when the beta cell compensatory response to IR is insufficient to regulate glucose metabolism(9). This may reduce the diagnostic utility of insulin measurements.

SIRS are grouped into three categories 1 . Disorders characterised by a primary impairment of adipocyte energy storage with adverse secondary impact on glucose handling by muscle and liver (Lipodystrophies) 2. Primary insulin signalling defects; and 3. Complex syndromes associated with IR. In this review we will briefly discuss recent progress in genetically classifying these syndromes, how they can be distinguished phenotypically and how they inform mechanistic understanding of more prevalent IR.

\section{Severe Insulin Resistance Syndromes}

\section{- The Lipodystrophies}


White adipose tissue is critical for the efficient storage of excess energy as triglyceride (TG) in lipid droplets. Lipodystrophies are a heterogeneous group of rare disorders characterised by a loss of adipose tissue and a depletion of lipid storage capacity $(10,11)$. The failure of this system places a demand on non-adipose sites, typically liver and muscle, to buffer excess circulating TG. The principle of adipose tissue expandability refers to the hypothesis that humans have a 'limited capacity' to increase the size and number of adipocytes(12, 13). In states of sustained positive energy balance, adipose tissue stores TG up to this threshold but once exceeded ectopic TG deposition occurs, and in turn results in impaired insulin action in target tissues like the liver and skeletal muscle(14).

Lipodystrophies are classified according to the extent of adipose loss (generalised or partial) and the primary cause of the disorder (genetic or acquired). Congenital generalised lipodystrophies(CGL) represent the severe end of the spectrum with a near complete loss of subcutaneous adipose tissue presenting from birth(15). AGPAT2 and BSCL2 were the earliest loci identified in Berardenelli-Seip syndromes with significant overlap between the phenotypes(16). Owing to the degree of adipose failure seen in CGL secondary complications manifest in childhood where in addition to developing the hallmarks of IR those effected have dyslipidaemia and non-alcoholic fatty liver disease(NAFLD) with the potential for developing steatohepatitis, cirrhosis and hepatic failure. In contrast to CGL, familial partial lipodystrophies (FPLD) are heritable disorders with varying degrees of subcutaneous fat loss, usually manifesting around puberty in girls and somewhat later in men. The best characterised subtypes include: 1) FPLD1 or Köbberling syndrome presenting with adipose tissue loss in the extremities but preserved or excess abdominal adiposity(17); 2) FPLD2, a monogenic disorder caused by LMNA mutations which in contrast to Köbberling syndrome classically presents with reduced subcutaneous adipose tissues in the limbs, abdomen and torso with adipose tissue accumulation in the face, neck and labia majora in females(18); 3 ) FPLD3 due to mutations in PPARG has a pattern of fat loss similar to FPLD1 although severe labile hypertriglyceridemia and hypertension are more frequent in affected individuals(19, 20). Metabolic complications vary depending on the extent of the lipodystrophic phenotype but NAFLD, IR, dyslipidaemia and secondary diabetes are common in all three. Recently a number of other genetic loci have been identified for both generalised and partial 
lipodystrophy (table 1). In two very rare subtypes due to mutations in CIDEC and PLIN1, the mutant proteins are almost exclusively expressed in adipocytes where they are directly involved in TG storage within lipid droplets, providing proof-in-principle that primary defects in adipose lipid storage are sufficient to cause the metabolic syndrome(11).

Acquired lipodystrophies have also been reported; not infrequently associated with other autoimmune disorders. Barraquer-Simons is well described as cephalocaudal fat loss, a deficiency in complement (C3), part of the innate immune response and mesangioproliferative glomerulonephritis(21). A metabolic phenotype is rarely seen in this condition, likely due to the sparing of gluteofemoral subcutaneous tissue (GSAT) depots which sequester excess TG. This finding is in contrast to the severity of metabolic disease observed in lipodystrophies where GSAT is depleted. Acquired generalised lipodystrophies(AGL) are very rare and may be idiopathic, associated with radiotherapy and/or drug exposure, or very rarely a cluster of conditions including haemolysis, hepatitis and low C4 complement levels(22). The precise pathophysiology of AGL has not been delineated though it is assumed to be autoimmune and the metabolic sequelae can be very severe(22, 23).

\section{- Insulin Receptor Signalling Defects}

Mutations in the INSR gene or a gene encoding a protein mediating its downstream signalling can cause severe IR. The most severe syndromes are associated with biallelic INSR mutations, namely Donohoe and Rabson-Mendenhall syndromes $(24,25)$. Both present after birth with failure to thrive, reduced muscle and adipose mass, and developmental delay. The ensuing hyperinsulinemia in the face of defective INSR function lead to the clinical manifestations of IR. Less deleterious, often heterozygous, mutations affecting the INSR may present with a milder, though still severe, phenotype manifesting post-pubertally; this presentation is often referred to as Type A IR(26). Type B IR differs physiologically from INSR mutations presenting acutely with features of severe IR due to the development of anti-insulin receptor antibodies. This condition is most often described in females of African ethnicity (27). Beyond the insulin receptor there is a complex cascade of intracellular proteins and kinases that if disrupted may 
also manifest with an insulin resistant phenotype (table 1); collectively these disorders can be classified under the term 'insulin receptoropathy'.

The study of patients with lipodystrophies and insulin receptoropathies has led to the identification of distinct clinically useful differences between the phenotypes enabling stratification prior to genetic testing - these include:

1. Dyslipidaemia and NAFLD are common complications of lipodystrophic syndromes and will almost certainly be present in patients who are insulin resistant at the time, whereas conditions of impaired proximal insulin receptor signalling are free of such metabolic derangement. The proposed mechanism relates to an increase in de novo lipogenesis (DNL) and the TG rich very low density lipoprotein cholesterol (VLDLC) release from the liver in response to hyperinsulinemia. In lipodytrophic conditions the partially functioning insulin signalling pathway fails to fully suppress glucose production but does appear to induce $\mathrm{DNL}(28)$. DNL is probably only part of the pathogenesis of NAFLD in this setting with increased non-esterified fatty acid delivery to the liver another likely contributor(29). In contrast, insulin receptoropathies do not manifest increased DNL (Figure 1)(28) .

2. Adiponectin is an adipokine produced exclusively by adipocytes. Although its function is not entirely clear circulating concentrations correlate with insulin sensitivity in most settings. When measured in lipodystrophic patients circulating adiponectin is low, whereas individuals with insulin receptoropathies have surprisingly normal or even elevated adiponectin concentrations(30). The implication being that adiponectin production by adipocytes is suppressed by the hyperinsulinemia of lipodystrophy and that a functioning insulin receptor is important to this activity. The observation that post insulin receptor signalling defects in AKT2 are associated with lower adiponectin levels similar to those in lipodystrophy suggests that a post-receptor process is involved(28). Adipose specific INSR knockout mice also manifest elevated adiponectin levels(31).

\section{- Complex syndromes of insulin resistance}


A number of complex syndromes have been described in which severe IR is a characteristic feature. The mechanism of IR in these disorders has often not been well characterised but there some intriguing mechanistic 'threads' eg. ciliary body function(32) and DNA repair mechanisms $(33,34)$. Although lipodystrophy and IR have been reported in a number of syndromes, adipose tissue loss is not a universal feature.

\section{Recent highlights}

\section{- Common genetic variation is associated with adipose expandability}

Genome-wide association studies have identified common variants implicated in many diseases. Beyond monogenic disorders of severe IR the most common presentation of IR is in individuals with increasing $\mathrm{BMI}$ and this is a major factor in the pathogenesis of type 2 diabetes mellitus(T2DM), yet the vast majority of genetic loci implicated in the pathogenesis of T2DM influence insulin secretion $(35,36)$.

Untangling the genetic loci associated with IR at a population level was greatly enhanced by using fasting insulin as the primary phenotype and then adjusting for BMI. Strikingly, several genomic regions associated with IR based on fasting insulin and adjusted for BMI correlated with lower HDL and increased TG levels $(37,38)$. Further, Scott et al noted that these alleles were associated with a lower BMI, total body fat, hip circumference and gynoid and leg fat based on DEXA fat mass quantification(39). More recently Lotta et al reported that SNPs in 53 distinct genomic regions were associated with increased fasting insulin(adjusted for BMI), higher TG and lower HDLc levels. A SNP score generated using the lead SNP in each of the 53 genomic regions was used to evaluate the strength of association between these loci and IR. Enrichment for the SNP score was associated significantly with lower insulin sensitivity as measured by hyperinsulinemic euglycemic clamps and frequently sampled oral glucose tolerance test, considered gold standard measurements of insulin sensitivity. The 53-SNP genetic score was also significantly associated with lower levels of leg and gynoid fat, and consequently with increased type 2 diabetes mellitus and coronary heart disease risk. 
Amongst a cohort of individuals who gained weight, those enriched for the SNP score were less likely to deposit fat in the gluteofemoral region(40). These observations suggest that enrichment for SNPs in IR loci is linked to reduced peripheral or hip adipose expandability, not dissimilar to the observations made in partial lipodystrophies. Individuals with FPLD1, a more prevalent partial lipodystrophy subtype are significantly enriched for the SNP score, suggesting a polygenic inheritance(40). The pattern of association observed in these studies strongly suggests that subtle differences in adipose tissue expandability contribute to IR in the general population, providing compelling human genetic support for the lipid overflow or expandability hypothesis.

\section{- Multiple Symmetric Lipomatosis}

Phenotype-genotype correlation in rare disease continues to offer a rewarding approach in the study of human biology. Multiple Symmetric Lipomatosis (MSL) is a condition of abnormal adipose tissue distribution first described in the 1800 's(41). Although the phenotype is heterogeneous it frequently presents with symmetrical fat accumulation in the upper back, neck and face. Metabolic complications (including insulin resistance, type 2 diabetes, dyslipidemia and NAFLD), peripheral and autonomic neuropathies are variably present (42). Early suggestions that defective mitochondrial function may be implicated in the pathogenesis of the condition emerged following observations of the association of MSL with myoclonus epilepsy and red ragged fibres (MERRF) a condition known to be caused by a mitochondrial DNA mutation(43). Recently, whole exome sequencing identified Mitofusin 2 (MFN2) as a candidate gene in three individuals with severe upper body symmetric lipomatosis, lower limb lipodystrophy and charcot marie tooth (CMT) axonal neuropathy(44). Another study describing three more affected patients affirmed these findings and the presence of a very specific missense mutation in at least one affected allele, namely the MFN2 p.R707W mutation(45). All cases described to date have either been homozygous for this variant or carried it alongside a second null allele. Mutations in other regions of the gene are strongly linked to CMT2a without lipodystrophy(45). Mitofusin 2 is a GTPase localised to the mitochondrial membrane and plays a critical role in the process of mitochondrial fusion through the formation of homotypic and heterotypic dimers with a similar GTPase Mitofusin 1(46). Individuals with MFN2 mutations have low leptin levels despite relatively normal 
adipocyte morphology $(44,47)$. The expanded adipose depots are due to unilocular adipocyte hyperplasia and negative for brown adipose tissue markers such as UCP1. Electron microscopy revealed abnormal mitochondria in adipose samples from affected patients and mRNA analysis highlighted a mitochondrial stress response in keeping with elevated circulating lactate levels(47). Interestingly the lowest levels of leptin expression were observed among patients with the most severe adipose phenotype(47). Leptin is widely acknowledged as a signal of adipose energy stores which increases and decreases with changes in fat mass, though exactly how each adipocyte regulates leptin synthesis and secretion remains unclear. Total leptin deficiency is rare but has a striking phenotype of extreme hyperphagia and hypothalamic dysfunction and it has been observed in patients (and mice) with mutations of the leptin gene and in generalised lipodystrophies where a paucity of functional adipose tissue accounts for the lack of leptin. In MFN2 associated MSL, we have

a condition associated with mitochondrial dysfunction in hyperplastic adipose tissue associated with very low leptin levels suggesting that mitochondrial function is an important determinant of leptin gene expression.

\section{- Insights into insulin receptor signalling}

A consistent feature of the INSR mutation phenotype is normal or elevated adiponectin and an absence of dyslipidaemia and NAFLD. PI3 kinases are intracellular enzymes regulating membrane phosphoinositide phosphorylation immediately downstream of the INSR and insulin receptor substrate (IRS) proteins, and have long been considered as prime candidates for monogenic IR. They are composed of distinct regulatory and catalytic subunits encoded for by different genes forming heterodimers and mediating intracellular signalling. There have been a number of PI3Kinase subclasses identified sharing homology in the catalytic subunit but differing in their regulatory elements. Class $1 \mathrm{~A}$ regulatory subunits are encoded by 3 different genes PI3KR1, PI3KR2 and PI3KR3(48). SHORT syndrome is a rare condition characterised by the presence of short stature, hyper flexibility, ocular depression, a developmental defect of the iris and an abnormality in teething, it is accompanied by partial lipodystrophy and IR. It was recently shown to arise from loss-of-function mutations in the PIK3R1 gene encoding the p85alpha regulatory subunit(49-51). The detailed study of individuals with SHORT syndrome arising due to heterozygous nonsense or missense 
mutations in PIK3R1 confirmed severe IR in affected cases without dyslipidaemia or fatty liver, and in all but one with significantly elevated adiponectin levels(52). These observations suggest that proximal insulin signalling defects are associated with preserved adiponectin expression rather than defects exclusive to the insulin receptor.

\section{- Tissue-specific IR}

It is noteworthy that not all defects in insulin signalling have an equal impact on liver and muscle. Dash et al described a family with a primary defect in a RAB-GAP protein that regulates the trafficking of GLUT4 to the cell surface, this resulted in severe post-prandial IR in the face of normal fasting glucose and insulin levels (largely determined by hepatic responses to insulin; which do not involve GLUT4)(53). Moltke et al have shown that a mutation in a muscle-specific isoform of the same gene is highly prevalent in Greenland Inuit populations where it results in selective post-prandial hyperinsulinemia and hyperglycemia(54).

\section{- Conclusions}

We have reviewed rare disorders of adipose tissue and primary insulin signalling defects causing severe IR emphasizing instances where the identification and study of affected individuals has yielded significant insights into the consequences of adipose dysfunction, as well as the relevance of this paradigm to prevalent forms of IR, and/or the complexities of insulin signalling. As is the case with MFN2 mutations, monogenic disorders continue to pose challenging scientific questions and efforts continue to untangle the molecular biology of such conditions. 


\begin{tabular}{|c|c|c|c|}
\hline Gene & Gene product and function & Phenotype & Ref \\
\hline \multicolumn{4}{|l|}{ Generalised Lipodystrophies } \\
\hline \multicolumn{4}{|l|}{ Congenital } \\
\hline AGPAT2 & $\begin{array}{l}\text { 1-acylglycerol-3phosphate } \mathrm{O} \text {-acyltransferase 2; ER protein } \\
\text { regulating triglyceride biosynthesis }\end{array}$ & \multirow[t]{2}{*}{$\begin{array}{l}\text { Generalised Lipoatrophy from birth, severe IR, dyslipidaemia, } \\
\text { NAFLD, low leptin and adiponectin. }\end{array}$} & \multirow[t]{2}{*}{$\begin{array}{l}(15,16,55 \\
56)\end{array}$} \\
\hline BSCL2 & Seipin; ER protein involved in lipid droplet biogenesis & & \\
\hline CAV1 & Caveolin-1; involved in formation of membrane caveolae & As above plus short stature & (57) \\
\hline PTRF & $\begin{array}{l}\text { Polymerase } 1 \text { and transcript release factor; localises to caveolae } \\
\text { regulating formation and stability }\end{array}$ & $\begin{array}{l}\text { Generalised lipoatrophy and muscular dystrophy with milder } \\
\text { metabolic phenotype. }\end{array}$ & (58) \\
\hline \multicolumn{4}{|l|}{ Acquired } \\
\hline $\begin{array}{l}\text { Idiopathic/Radiotherapy/Drug- } \\
\text { related/autoimmune }\end{array}$ & NA & Generalised lipoatrophy, IR & (22) \\
\hline \multicolumn{4}{|l|}{ Partial Lipodystrophies } \\
\hline \multicolumn{4}{|l|}{ Familial } \\
\hline FPLD1 & $\mathrm{NA}$; likely polygenic in many cases & $\begin{array}{l}\text { Peripheral lipoatrophy, prominent abdominal adiposity, IR. Low } \\
\text { adiponectin }\end{array}$ & (59) \\
\hline LMNA & Lamin A/C; Nuclear envelope protein & $\begin{array}{l}\text { Limb, gluteofemoral and truncal subcutaneous fat loss, IR. } \\
\text { Sparing adipose tissue at the neck and face, low adiponectin. }\end{array}$ & $(59,60)$ \\
\hline PPARG & $\begin{array}{l}\text { Peroxisome proliferator activated receptor gamma; Nuclear } \\
\text { transcription factor regulating adipocyte differentiation and } \\
\text { function }\end{array}$ & $\begin{array}{l}\text { Peripheral lipoatrophy prominent, variable abdominal adiposity, } \\
\text { hypertension, hypertriglyceridemia, low adiponectin }\end{array}$ & $(19,20)$ \\
\hline PLIN1 & $\begin{array}{l}\text { Perilipin 1; Lipid droplet coat protein involved in the regulation } \\
\text { of lipolysis }\end{array}$ & Limb and gluteofemoral fat loss, IR. & (61) \\
\hline CIDEC & $\begin{array}{l}\text { Cell death inducing DFFA like effector C; required for unilocular } \\
\text { lipid droplet formation in adipocytes }\end{array}$ & Peripheral lipoatrophy with some multilocular adipocytes & (62) \\
\hline AKT2 & $\begin{array}{l}\text { Akt serine/threonine kinase 2; key proximal insulin signalling } \\
\text { intermediate }\end{array}$ & IR, Dyslipidaemia and fatty liver, low adiponectin, lipodystrophy & (63) \\
\hline PCYT1A & $\begin{array}{l}\text { Phosphate cytidylyltransferase 1, choline, al pha; involved in } \\
\text { phosphatidylcholine synthesis }\end{array}$ & Lipoatrophy, IR, low adiponectin, short stature. & (64) \\
\hline \multicolumn{4}{|l|}{ Acquired } \\
\hline Autoimmune & NA & $\begin{array}{l}\text { Cephalocaudal lipoatrophy, minimal metabolic phenotype, Low } \\
\text { C3, MPGN +/- other autoimmune disease }\end{array}$ & $(21,22)$ \\
\hline HIV/ARV associated & NA & $\begin{array}{l}\text { Progressive thinning of subcutaneous adipose tissue in the face, } \\
\text { arms and legs. Increased truncal and abdominal adiposity may } \\
\text { also be present }\end{array}$ & \\
\hline \multicolumn{4}{|l|}{ Insulin Receptoropathies } \\
\hline \multicolumn{4}{|l|}{ Complete/Proximal } \\
\hline INSR & Insulin receptor; Tyrosine Kinase receptor for insulin & $\begin{array}{l}\text { Severe IR without dyslipidaemia or NAFLD, normal or high } \\
\text { adiponectin, SHBG, IGF1 }\end{array}$ & (65) \\
\hline Anti-insulin receptor Antibodies & NA & IR, normal or high Adiponectin +/-Autoimmune disease. & $(27,66)$ \\
\hline \multicolumn{4}{|l|}{ Partial/Distal } \\
\hline AKT2 & See above & See above & \\
\hline TBC1D4 & $\begin{array}{l}\text { TBC domain family member 4; Rab-GTPase activating protein, } \\
\text { regulates insulin dependent trafficking of GLUT4 }\end{array}$ & Post prandial IR & (53) \\
\hline
\end{tabular}




\begin{tabular}{|l|l|l|l|}
\hline POLD1 & DNA Polymerase delta 1 & $\begin{array}{l}\text { Mandibulo hypoplasia, deafness, progeria, lipodystrophy (MDLP } \\
\text { syndrome) }\end{array}$ & (33, 67) \\
\hline PIK3R1 & $\begin{array}{l}\text { Phosphoinositide-3-kinase 85alpha regulatory subunit; key } \\
\text { insulin signalling intermediate }\end{array}$ & $\begin{array}{l}\text { Short stature, hyper extensibility, ocular depression, rieger } \\
\text { anomaly, teething delay (SHORT syndrome) }\end{array}$ & (49, 50) \\
\hline WRN & Werner syndrome RecQ like helicase; DNA helicase & $\begin{array}{l}\text { Lipodystrophy, premature aging (Werner syndrome) } \\
\text { in microtubule/ciliary function }\end{array}$ & $\begin{array}{l}\text { Rod-cone dystrophy, hepatic and renal dysfunction, deafness, IR } \\
\text { (Alstrom's syndrome) }\end{array}$ \\
\hline ALMS1 & Bloom syndrome RecQ like helicase; DNA helicase & $\begin{array}{l}\text { Lipodystrophy, Short stature, telangiectasia, IR (Bloom's } \\
\text { syndrome) }\end{array}$ & (70) \\
\hline BLM & Zinc metallopeptidase STE24; regulates posttranslational \\
ZMPSTE24 (AND LMNA) & Meavage of prelamin & (71) \\
\hline
\end{tabular}

\section{Acknowledgements}

S.O'R. and D.B.S. are supported by the Wellcome Trust (grants WT095515, WT 107064), the MRC Metabolic Disease Unit, the National Institute for Health Research (NIHR) Cambridge Biomedical Research Centre and NIHR Rare Disease Translational Research Collaboration.

The authors declare no conflict of interest. 


\section{References}

1. Wallace TM, Matthews DR. The assessment of insulin resistance in man. Diabetic Medicine. 2002;19:527-34.

2. Karam JH, Grodsky GM, Forsham PH. Excessive insulin response to glucose in obese subjects as measured by immunochemical assay. Diabetes. 1963;12:197-204.

3. Semple RK, Savage DB, Cochran EK, Gorden P, O'Rahilly S. Genetic syndromes of severe insulin resistance. Endocr Rev. 2011;32(4):498-514.

4. Yosipovitch G, DeVore A, Dawn A. Obesity and the skin: skin physiology and skin manifestations of obesity. J Am Acad Dermatol. 2007;56(6):901-16; quiz 17-20.

5. Sari R, Akman A, Alpsoy E, Balci MK. The metabolic profile in patients with skin tags. Clin Exp Med. 2010;10(3):193-7.

6. Cruz PD, Jr., Hud JA, Jr. Excess insulin binding to insulin-like growth factor receptors: proposed mechanism for acanthosis nigricans. J Invest Dermatol. 1992;98(6 Suppl):82S-5S. 7. Barber TM, Dimitriadis GK, Andreou A, Franks S. Polycystic ovary syndrome: insight into pathogenesis and a common association with insulin resistance. Clinical Medicine. 2015;15(6):72-6.

8. *Brown RJ, Joseph J, Cochran E, Gewert C, Semple R, Gorden P. Type B Insulin Resistance Masquerading as Ovarian Hyperthecosis. J Clin Endocrinol Metab.

2017;102(6):1789-91.

This is a clinical practice guideline outlining the current approaches to diagnosis and management of lipodystrophy syndromes in children and adults.

9. Kahn SE. The relative contributions of insulin resistance and beta-cell dysfunction to the pathophysiology of Type 2 diabetes. Diabetologia. 2003;46(1):3-19.

10. Brown RJ, Araujo-Vilar D, Cheung PT, Dunger D, Garg A, Jack M, et al. The Diagnosis and Management of Lipodystrophy Syndromes: A Multi-Society Practice Guideline. The Journal of Clinical Endocrinology and Metabolism. 2016;101(12):4500-11.

11. *Robbins AL, Savage DB. The genetics of lipid storage and human lipodystrophies. Trends Mol Med. 2015;21(7):433-8.

This is a brief review of lipodystophic disorders highlighting the importance of the lipid droplet and energy storage in metabolic disease.

12. Danforth $\mathrm{E}$, Jr. Failure of adipocyte differentiation causes type II diabetes mellitus? Nat Genet. 2000;26(1):13.

13. Virtue S, Vidal-Puig A. Adipose tissue expandability, lipotoxicity and the Metabolic Syndrome--an allostatic perspective. Biochim Biophys Acta. 2010;1801(3):338-49.

14. Samuel VT, Shulman GI. Mechanisms for insulin resistance: common threads and missing links. Cell. 2012;148(5):852-71.

15. Agarwal AK, Simha V, Oral EA, Moran SA, Gorden P, O'Rahilly S, et al. Phenotypic and genetic heterogeneity in congenital generalized lipodystrophy. J Clin Endocrinol Metab.

2003;88(10):4840-7.

16. Magre J, Delepine M, Khallouf E, Gedde-Dahl T, Jr., Van Maldergem L, Sobel E, et al. Identification of the gene altered in Berardinelli-Seip congenital lipodystrophy on chromosome 11q13. Nat Genet. 2001;28(4):365-70. 
17. Guillin-Amarelle C, Sanchez-Iglesias S, Castro-Pais A, Rodriguez-Canete L, OrdonezMayan L, Pazos M, et al. Type 1 familial partial lipodystrophy: understanding the Kobberling syndrome. Endocrine. 2016;54(2):411-21.

18. Garg A, Peshock RM, Fleckenstein JL. Adipose Tissue Distribution Pattern in Patients with Familial Partial Lipodystrophy (Dunnigan Variety). Journal of Clinical Endocrinology and Metabolism. 1999;84(1):170-4.

19. Agarwal AK, Garg A. A Novel Heterozygous Mutation in the Peroxisome ProliferatorActivated Receptor gamma Gene in a Patient with Familial Partial Lipodystrophy. Journal of Clinical Endocrinology and Metabolism. 2002;87(1):408-11.

20. Savage DB, Tan GD, Acerini CL, Jebb SA, Agostini M, Gurnell M, et al. Human Metabolic Syndrome Resulting From Dominant-Negative Mutations in the Nuclear Receptor Peroxisome Proliferator Activated Receptor gamma. Diabetes. 2003;52:910-7.

21. Misra A, Peethambaram A, Garg A. Clinical features and metabolic and autoimmune derangements in acquired partial lipodystrophy: report of 35 cases and review of the literature. Medicine (Baltimore). 2004;83(1):18-34.

22. Savage DB, Semple RK, Clatworthy MR, Lyons PA, Morgan BP, Cochran EK, et al. Complement abnormalities in acquired lipodystrophy revisited. J Clin Endocrinol Metab. 2009;94(1):10-6.

23. Misra A, Garg A. Clinical Features and Metabolic Derangements in Acquired Generalized Lipodystrophy Case Reports and Review of the Literature. Medicine (Baltimore). 2003;82(2):129-46.

24. Donohue WL, Uchida I. Leprechaunism: a euphemism for a rare familial disorder. J Pediatr. 1954;45(5):505-19.

25. Rabson SM, Mendenhall EN. Familial hypertrophy of pineal body, hyperplasia of adrenal cortex and diabetes mellitus; report of 3 cases. Am J Clin Pathol. 1956;26(3):283-90. 26. Musso C, Cochran E, Moran SA, Skarulis MC, Oral EA, Taylor S, et al. Clinical course of genetic diseases of the insulin receptor (type $A$ and Rabson-Mendenhall syndromes): a 30year prospective. Medicine (Baltimore). 2004;83(4):209-22.

27. Arioglu E, Andewelt A, Diabo C, Bell M, Taylor SI, Gorden P. Clinical Course of the Syndrome of Autoantibodies to the Insulin Receptor (Type B Insulin Resistance); A 28 Year Perspective. Medicine (Baltimore). 2002;81(2):87-100.

28. Semple RK, Sleigh A, Murgatroyd PR, Adams CA, Bluck L, Jackson S, et al. Postreceptor insulin resistance contributes to human dyslipidemia and hepatic steatosis. J Clin Invest. 2009;119(2):315-22.

29. Lewis GF, Uffelman KD, Szeto LW, Weller B, Steiner G. Interactions between Free Fatty Acids and Insulin in the Acute Control of Very Low Density Lipoprotein Production in Humans. Journal of Clinical Investigation. 1995;95:158-66.

30. Semple RK, Cochran EK, Soos MA, Burling KA, Savage DB, Gorden P, et al. Plasma Adiponectin as a Marker of Insulin Receptor Dysfunction. Diabetes Care. 2008;31(5).

31. Blüher M, Michael MD, Peroni OD, Ueki K, Carter N, Kahn BB, et al. Adipose Tissue Selective Insulin Receptor Knockout Protects against Obesity and Obesity-Related Glucose Intolerance. Developmental Cell. 2002;3(1):25-38.

32. Girard D, Petrovsky N. Alstrom syndrome: insights into the pathogenesis of metabolic disorders. Nat Rev Endocrinol. 2011;7(2):77-88.

33. Weedon MN, Ellard S, Prindle MJ, Caswell R, Lango Allen H, Oram R, et al. An inframe deletion at the polymerase active site of POLD1 causes a multisystem disorder with lipodystrophy. Nat Genet. 2013;45(8):947-50. 
34. Yamada K, Ikegami H, Yoneda H, Miki T, Ogihara T. All patients with Werner's syndrome are insulin resistant, but only those who also have impaired insulin secretion develop overt diabetes. Diabetes Care. 1999;22(12):2094-5.

35. Kahn SE, Hull RL, Utzschneider KM. Mechanisms linking obesity to insulin resistance and type 2 diabetes. Nature. 2006;444(7121):840-6.

36. Dimas AS, Lagou V, Barker A, Knowles JW, Magi R, Hivert MF, et al. Impact of type 2 diabetes susceptibility variants on quantitative glycemic traits reveals mechanistic heterogeneity. Diabetes. 2014;63(6):2158-71.

37. Manning AK, Hivert MF, Scott RA, Grimsby JL, Bouatia-Naji N, Chen $\mathrm{H}$, et al. A genome-wide approach accounting for body mass index identifies genetic variants influencing fasting glycemic traits and insulin resistance. Nat Genet. 2012;44(6):659-69.

38. Scott RA, Lagou V, Welch RP, Wheeler E, Montasser ME, Luan J, et al. Large-scale association analyses identify new loci influencing glycemic traits and provide insight into the underlying biological pathways. Nat Genet. 2012;44(9):991-1005.

39. Scott RA, Fall T, Pasko D, Barker A, Sharp SJ, Arriola L, et al. Common genetic variants highlight the role of insulin resistance and body fat distribution in type 2 diabetes, independent of obesity. Diabetes. 2014;63(12):4378-87.

40. ** Lotta LA, Gulati P, Day FR, Payne F, Ongen H, van de Bunt M, et al. Integrative genomic analysis implicates limited peripheral adipose storage capacity in the pathogenesis of human insulin resistance. Nat Genet. 2017;49(1):17-26.

This study provides human genetic evidence that differences in adipose tissue expandability contribute to insulin resistance in the general population.

41. Madelung OW. Uber den fetthals (diffuses lipom des halses) Arch Klin Chir. 1888:106-30.

42. Herbst KL. Rare adipose disorders (RADs) masquerading as obesity. Acta Pharmacol Sin. 2012;33(2):155-72.

43. Holme E, Larsson N, Oldfors A, Tulinius M, Stenman G. Multiple symmetric lipomas with high levels of mtDNA with the tRNA(Lys) A-->G(8344) mutation as the only manifestation of disease in a carrier of myoclonus epilepsy and ragged-red fibers (MERRF) syndrome. Am J Human Genet. 1993;52:551-6.

44. *Sawyer SL, Cheuk-Him Ng A, Innes AM, Wagner JD, Dyment DA, Tetreault M, et al. Homozygous mutations in MFN2 cause multiple symmetric lipomatosis associated with neuropathy. Hum Mol Genet. 2015;24(18):5109-14.

This study was the first to suggest that MFN2 mutations were responsible for some cases of multiple symmetric lipomatosis.

45. Calvo J, Funalot B, Ouvrier RA, Lazaro L, Toutain A, De Mas P, et al. Genotypephenotype correlations in Charcot-Marie-Tooth disease type 2 caused by mitofusin 2 mutations. Arch Neurol. 2009;66(12):1511-6.

46. Chen H, Detmer SA, Ewald AJ, Griffin EE, Fraser SE, Chan DC. Mitofusins Mfn1 and $\mathrm{Mfn} 2$ coordinately regulate mitochondrial fusion and are essential for embryonic development. J Cell Biol. 2003;160(2):189-200.

47. ${ }^{* *}$ Rocha N, Bulger DA, Frontini A, Titheradge H, Gribsholt SB, Knox R, et al. Human biallelic MFN2 mutations induce mitochondrial dysfunction, upper body adipose hyperplasia, and suppression of leptin expression. Elife. 2017;6. 
This study of humans with MFN2 mutations confirmed the reported link with multiple symmetric lipomatosis and provided evidence that mitochondrial function plays a role in regulating leptin expression.

48. Hawkins PT, Anderson KE, Davidson K, Stephens LR. Signalling through Class I PI3Ks in mammalian cells. Biochem Soc Trans. 2006;34(Pt 5):647-62.

49. Chudasama KK, Winnay J, Johansson S, Claudi T, Konig R, Haldorsen I, et al. SHORT syndrome with partial lipodystrophy due to impaired phosphatidylinositol 3 kinase signaling. Am J Hum Genet. 2013;93(1):150-7.

50. Thauvin-Robinet C, Auclair M, Duplomb L, Caron-Debarle M, Avila M, St-Onge J, et al. PIK3R1 Mutations Cause Syndromic Insulin Resistance with Lipoatrophy. Am J Hum Genet. 2013;93(1):141-9.

51. Dyment DA, Smith AC, Alcantara D, Schwartzentruber JA, Basel-Vanagaite L, Curry CJ, et al. Mutations in PIK3R1 cause SHORT syndrome. Am J Hum Genet. 2013;93(1):158-66.

52. **Huang-Doran I, Tomlinson P, Payne F, Gast A, Sleigh A, Bottomley W, et al. Insulin resistance uncoupled from dyslipidemia due to C-terminal PIK3R1 mutations. JCI Insight. 2016;1(17):e88766.

This paper suggests that the uncoupling of insulin resisitance from dyslipidaemia takes place at a level distal to the insulin receptor.

53. Dash S, Sano H, Rochford JJ, Semple RK, Yeo G, Hyden CS, et al. A truncation mutation in TBC1D4 in a family with acanthosis nigricans and postprandial hyperinsulinemia. Proc Natl Acad Sci U S A. 2009;106(23):9350-5.

54. Moltke I, Grarup N, Jorgensen ME, Bjerregaard P, Treebak JT, Fumagalli M, et al. A common Greenlandic TBC1D4 variant confers muscle insulin resistance and type 2 diabetes. Nature. 2014;512(7513):190-3.

55. Agarwal AK, Arioglu E, De Almeida S, Akkoc N, Taylor SI, Bowcock AM, et al. AGPAT2 is mutated in congenital generalized lipodystrophy linked to chromosome 9q34. Nat Genet. 2002;31(1):21-3.

56. Antuna-Puente B, Boutet E, Vigouroux C, Lascols O, Slama L, Caron-Debarle M, et al. Higher adiponectin levels in patients with Berardinelli-Seip congenital lipodystrophy due to seipin as compared with 1-acylglycerol-3-phosphate-o-acyltransferase-2 deficiency. J Clin Endocrinol Metab. 2010;95(3):1463-8.

57. Kim CA, Delepine M, Boutet E, El Mourabit H, Le Lay S, Meier M, et al. Association of a homozygous nonsense caveolin-1 mutation with Berardinelli-Seip congenital lipodystrophy. J Clin Endocrinol Metab. 2008;93(4):1129-34.

58. Hayashi YK, Matsuda C, Ogawa M, Goto K, Tominaga K, Mitsuhashi S, et al. Human PTRF mutations cause secondary deficiency of caveolins resulting in muscular dystrophy with generalized lipodystrophy. J Clin Invest. 2009;119(9):2623-33.

59. Kopperling J, Dunnigan MG. Familial partial lipodystrophy: two types of an X linked dominant syndrome, lethal in the hemizygous state. Journal of Medical Genetics. 1986;23:120-7.

60. Cao H, Hegele RA. Nuclear lamin A/C R482Q mutation in Canadian kindreds with Dunnigan-type familial partial lipodystrophy. Human Molecular Genetics. 2000;9(1):109-12.

61. Gandotra S, Le Dour C, Bottomley W, Cervera P, Giral P, Reznik Y, et al. Perilipin Deficiency and Autosomal Dominant Partial Lipodystrophy. New England Journal of Medicine. 2011;364(8):740-8. 
62. Rubio-Cabezas O, Puri V, Murano I, Saudek V, Semple RK, Dash S, et al. Partial lipodystrophy and insulin resistant diabetes in a patient with a homozygous nonsense mutation in CIDEC. EMBO Mol Med. 2009;1(5):280-7.

63. George S, Rochford JJ, Wolfrum C, Gray SL, Schinner S, Wilson JC, et al. A family with severe insulin resistance and diabetes due to a mutation in AKT2. Science.

2004;304(5675):1325-8.

64. Payne F, Lim K, Girousse A, Brown RJ, Kory N, Robbins A, et al. Mutations disrupting the Kennedy phosphatidylcholine pathway in humans with congenital lipodystrophy and fatty liver disease. Proc Natl Acad Sci U S A. 2014;111(24):8901-6.

65. Musso C, Cochran E, Moran SA, Skarulis MC, Arioglu Oral E, Taylor S, et al. Clinical Course of Genetic Diseases of the Insulin Receptor (Type A and Rabson-Mendenhall Syndromes) A 30-Year Prospective. Medicine (Baltimore). 2004;83(4).

66. Kahn CR, Flier JS, Bar RS, Archer JA, Gorden P, Martin MM, et al. The syndromes of insulin resistance and acanthosis nigricans. Insulin-receptor disorders in man. N Engl J Med. 1976;294(14):739-45.

67. Shastry S, Simha V, Godbole K, Sbraccia P, Melancon S, Yajnik CS, et al. A novel syndrome of mandibular hypoplasia, deafness, and progeroid features associated with lipodystrophy, undescended testes, and male hypogonadism. J Clin Endocrinol Metab. 2010;95(10):E192-7.

68. Yu CE, Oshima J, Fu YH, Wijsman EM, Hisama F, Alisch R, et al. Positional cloning of the Werner's syndrome gene. Science. 1996;272(5259):258-62.

69. Collin GB, Marshall JD, Ikeda A, So WV, Russell-Eggitt I, Maffei P, et al. Mutations in ALMS1 cause obesity, type 2 diabetes and neurosensory degeneration in Alstrom syndrome. Nat Genet. 2002;31(1):74-8.

70. Ellis NA, German J. Molecular genetics of Bloom's syndrome. Hum Mol Genet. 1996;5 Spec No:1457-63.

71. Novelli G, Muchir A, Sangiuolo F, Helbling-Leclerc A, D'Apice MR, Massart C, et al. Mandibuloacral dysplasia is caused by a mutation in LMNA-encoding lamin A/C. Am J Hum Genet. 2002;71(2):426-31. 
Figure 1: Monogenic disorders of insulin receptor signalling as a model for the uncoupling of insulin's metabolic actions.

Insulin binds to its transmembrane receptor activating a downstream signalling cascade regulating the hormone's metabolic functions to increase glucose transport into the cell and consequently glycogen and lipid synthesis while suppressing hepatic glucose production. Defects (red shading) affecting the insulin receptor (INSR; Type A insulin resistance, Donohue and Rabson-Mendenhall syndromes), PI3Kinase p85alpha catalytic subunit (SHORT syndrome) and AKT2 lead to an uncoupling of insulin's glucose lowering effects from SREPB1c regulated de novo lipogenesis. IRS, insulin receptor substrate; PIP2/3, phosphatidylinositol(4,5)-bisphosphate 2/3; mTOR1, mammalian target of rapamycin complex 1; SREBP1c, sterol regulatory element binding protein 1; FOXO1, forkhead box protein 01 and GSK3, glycogen synthase kinase 3. 